\title{
La teleología como un obstáculo epistemológico en la enseñanza de la evolución.
}

Por: Cháves Mejía Germán Alberto. ${ }^{1}$

"Si vamos a enseñar 'la ciencia de la creación' como una alternativa a la evolución entonces, también deberíamos enseñar la teoría de la cigüeña como una alternativa a la reproducción biológica". (Hayes, 2000. p.178)

"La ignorancia genera confianza más frecuentemente que el conocimiento, son aquellos que saben poco, y no esos que saben más, quienes tan positivamente afirman que éste o aquel problema nunca será resuelto por la ciencia".

\section{INTRODUCCIÓN}

(Darwin, 2004 [1871]. p. 199)

Si bien la enseñanza de la evolución hace parte de los programas curriculares que se desarrollan en la educación primaria, secundaria y algunos programas universitarios en Colombia, esta enseñanza tropieza frecuentemente con obstáculos epistemológicos como lo son: las arraigadas creencias religiosas como el creacionismo (para explicar el origen y la inmutabilidad de lo vivo), la malinterpretación de la teoría evolutiva darwiniana, las explicaciones del fenómeno viviente basadas en animismos, vitalismos, mecanicismos finalistas, etc.

Este ensayo pretende hacer un especial énfasis en como el uso de explicaciones teleológicas para explicar diferentes aspectos del fenómeno viviente puede llegar a ser un obstáculo epistemológico muy relevante en la enseñanza de la evolución. Así pues, en este ensayo se presentarán diferentes aspectos de la teleología y su relación con la teoría de la evolución, desarrollando un análisis que permita esclarecer cómo dichos aspectos se pueden convertir en obstáculos epistemológicos en la enseñanza de la evolución.

\section{TELEOLOGÍA}

Como lo expresa Echandía (1995), etimológicamente tiene sus raíces en logos (teoría, explicación) y telos (fin). Los filósofos han presentado dos teorías opuestas para la comprensión de los cambios que ocurren en la Naturaleza: la mecanicista y la finalista o teleológica; en la primera (explicación cartesiana), los fenómenos concernientes a lo vivo, se explican pensando el cuerpo como un mecanismo, parecido a relojes, molinos, fuentes artificiales, artificios que se mueven en virtud de sus propios medios, es decir, montados sobre sí mismos.

${ }^{1}$ Biólogo, Universidad Nacional, Bogotá. Estudiante de Especialización en Enseñanza de la Biología, Universidad Pedagógica Nacional, Bogotá. E-mail gchavesm@ecci.edu.co 
De este modo, Descartes, quiere erradicar toda teleología ${ }^{2}$ con la analogía cuerpo-máquina, pues implicaría la intervención de lo que él llama formas ocultas, defendidas por los aristotélicos. En la explicación finalista o teleológica basada en las causas aristotélicas se conserva la idea o la noción de que sólo podemos comprender el cambio si nos referimos a la causa final (Bacarlet y Fuentes, 2007).

Según la filosofía aristotélica, las cosas del mundo y los cambios que les ocurren pueden existir por la naturaleza, el arte, la técnica, o el azar. Excluyendo los objetos que ocurren por azar o por naturaleza, el otro tipo de objetos, los seres artificiales tienen fines, puesto que han sido erigidos para algo. En cuanto a la cuestión de las cosas naturales; es característico del punto de vista de la filosofía aristotélica y posteriormente desde la escolástica en Santo Tomás, la defensa de la existencia de finalidad en todo objeto natural y en los cambios o movimientos naturales.

A la luz de las explicaciones teleológicas, el fin de la semilla es convertirse en árbol; cada ser natural tiene una finalidad que está determinada por su forma o esencia y a la cual aspira y de la que se dice que está en potencia, incluso los seres inorgánicos manifiestan fines en sus movimientos pues aspiran a situarse en su lugar natural (cuando una piedra cae se mueve con la finalidad de estar en el suelo, que es su lugar natural; cuando el humo asciende lo hace para situarse arriba, que es su lugar natural...). De modo que la teleología podría considerarse como la doctrina que considera indispensable para la comprensión de la realidad la referencia a los fines o motivos por lo que ocurre algo.

Sin embargo, como lo expresa Mayr (2006), a menudo se ha calificado erróneamente a Aristóteles como finalista, e incluso se ha denominado a la teleología cósmica como una perspectiva aristotélica. Es probable que el telos de Aristóteles no tenga nada que ver con el propósito del hombre o de Dios, sino más bien que el neoplatonismo impuesto por el judeocristianismo sea el responsable de la visión del mundo desde la perspectiva de la teleología cósmica. La anterior, aparente confusión, puede ser causada por una lectura errónea y continuista de la influencia aristotélica en el pensamiento teleológico medieval al "sustituir la historia de las ciencias por las ciencias según su historia" (Canguilhem, 1988. p.17). Sea cual fuere la posición de Aristóteles, el interés de éste articulo no es cómo surgió la teleología cósmica, sino cómo ésta se puede convertir en un obstáculo epistemológico en la enseñanza de la evolución.

\section{TELEOLOGÍA Y EVOLUCIÓN}

Como afirma Mayr: "es muy probable que ninguna otra ideología haya influido sobre la Biología más profundamente que el pensamiento teleológico” (1974; 1988; 1992, 2006 p.46).

\footnotetext{
${ }^{2}$ Se puede pensar que la visión mecanicista es de corte teleológico, ya que toda máquina está creada para "algo", sin embargo hay que tener en cuenta que Descartes pretende dar una explicación de la naturaleza y del universo en general a través de argumentos exclusivamente mecánicos; es decir, todo debe explicarse solamente por medio de la física y las matemáticas, lo cual implica, entre otras cosas, excluir toda reminiscencia de finalidad, de telos, así como también toda actividad espiritual al seno de la materia (Bacarlet, M. y Fuentes R. 2007, pp.163-165).
} 
Este tipo de cosmovisión finalista tiene sus orígenes, en el pensamiento aristotélico que sería adoptado y adaptado por el cristianismo y luego sería criticado y contrastado con el surgimiento de nuevas concepciones filosóficas de la Edad Moderna y del pensamiento evolutivo darwiniano.

En la Edad Moderna se pensaba que la explicación por causas finales era antropomórfica, pues del hecho de que el hombre conozca por causas finales (los procesos, artefactos, constructos mentales etc. son teleológicos), no se deriva que el universo funcione con este principio. Es por ello que surge un movimiento, el mecanicismo, que intentaría explicar el mundo por causas eficientes (formales y materiales). Esto es lo que posibilitará el nacimiento de la ciencia moderna.

Cuando Charles Darwin escribió El origen de las Especies, comenzó una revolución. La tesis básica en su texto apuntaba a que la vida sobre la Tierra, tal y como la conocemos, es producto de la selección natural, actuando durante largos períodos de tiempo. Para llegar a tal conclusión se basó principalmente en los textos de Charles Lyell sobre geología, en conjunción con una idea de Thomas Malthus de su Ensayo sobre el principio de la población. Sin embargo, es importante anotar que "la idea de selección natural se construyó con base en la analogía con la selección artificial, con las teorías económica de Adam Smith y demográfica de Malthus, sin mencionar otro tipo de abstracciones" (Castro, 2003. p.9), es decir, la teoría de la selección natural tiene sus orígenes en una visión teleológica, como lo es la selección artificial, no obstante, gracias a la genialidad de Darwin, trascendió la teleología cósmica, al despojar a la naturaleza de diseño o intenciones de tipo sobrenatural.Darwin ideó el concepto de selección natural como símil con el trabajo realizado por agricultores y criadores de animales domésticos, como también a su afición a la crianza de palomas (Darwin era colombófilo) (Castro, 2003), a través del uso de analogías con la selección artificial, pudo comprender el mecanismo de la naturaleza para producir la inmensa variedad de seres vivos, pero él fue mas allá, comprendió que las "fuerzas" que hacían posible los cambios en los seres vivos, como en la materia inerte, eran de origen puramente físico y que por lo tanto no tenían ningún tipo de intención o finalidad, es decir su analogía entre la selección artificial (teleológica) y la natural, tenían explicaciones causales diametralmente diferentes.

Podemos parafrasear a Darwin, utilizando una terminología más renovada, diciendo que postuló el principio de que: los individuos de una especie que obtienen de una serie de rasgos aleatorios (mutaciones) una superior capacidad adaptativa ( de mantenerse vivos y poderse reproducir -eficacia biológica-) que otros miembros de la misma especie con los cuales compiten por el alimento serán los que transmitirán su carga genética a las siguientes generaciones, logrando así, a lo largo de mucho tiempo, la variación de las especies sobre la Tierra.

Como puede verse, la explicación de Darwin es naturalista y eficientista. No explica la variación de las especies con base en unos fines determinados, los cuales se persiguen. Esto iba en contra de la doctrina creacionista defendida por la iglesia, lo cual provocó el rechazo de esta explicación desde este ámbito.

Se puede observar que la teleología que enfatiza las causas finales está en franca oposición al pensamiento darwinista y lo que de él se deriva. 


\section{PROCESOS TELEOLÓGICOS, TELEONÓMICOS Y TELEOMÁTICOS EN LA ENSEÑANZA DE LA EVOLUCIÓN.}

Como lo señala Mayr (2006), a menudo para describir ciertos procesos biológicos se utiliza el sentido teleológico como un objetivo bien definido con una finalidad que puede ser previsible cuando el proceso se inicia y que puede llegar a inducir un razonamiento teológico o metafísico inverificable por la ciencia. Es a veces común escuchar las siguientes frases en estudiantes y profesores de Biología "los osos polares han desarrollado su color blanco para poder camuflarse mejor", "los murciélagos han desarrollado sonares para poder orientarse". Este tipo de razonamientos tratan de explicar el por qué de ciertos adaptaciones biológicas, recurriendo a una finalidad que hace que se cumpla un objetivo o que bien está en la naturaleza de los seres vivos (vitalismo) o que está dirigida por el plan de un diseñador sobrenatural (explicación metafísica). En contraste, el por qué de estos comportamientos o procesos biológicos se pueden dilucidar haciendo acopio de la causación evolutiva y su explicación que nos conducen a diferenciar muy bien los procesos teleomáticos y teleonómicos de los procesos teleológicos propiamente dichos.

Los procesos teleomáticos, como lo señala Mayr (1995; 2006), son los que se direccionan hacia un fin de una manera automática controlados por las leyes naturales que rigen los procesos físicos, como, por ejemplo, el enfriamiento de un metal caliente o el curso de un río desde su origen hasta su desembocadura en el océano, pero que de ninguna manera estos procesos se desarrollan persiguiendo un fin consciente o la realización de un programa con un objetivo determinado. Esta última posición fue adoptada por Nagel (1977) y Engels (1982) para la explicación de ciertos fenómenos, y Mayr (2006) la contrasta y la rebate muy clara y elegantemente a través del siguiente ejemplo: si una piedra cae por una montaña y mata a alguien, Engels y Nagel tendrían que concluir que la piedra estaba programada para realizar este homicidio, lo cual cae obviamente en lo absurdo.

Los procesos teleonómicos son aquellos que dan una aparente sensación de que existe una finalidad hacia un objetivo de ciertos procesos o conductas biológicas. Por ejemplo, procesos como el cortejo o la migración o el desarrollo embriológico están controlados por programas genéticos o programas sistémicos somáticos (existe discusión sobre si los programas somáticos están totalmente supeditados a los genéticos, o no lo están, en cualquier caso esa discusión no hace parte del problema que trata este ensayo). Dichos programas se despliegan hasta desarrollar en los individuos biológicos una finalidad, pero no una finalidad enfocada hacia el cumplimiento de un objetivo por una programación consciente del proceso. Por ejemplo, el desarrollo de un huevo fecundado es el despliegue de un programa genético (y ciertas condiciones ambientales), el cual ha sido desarrollado por millones de años de evolución por selección natural (no consciente) y que hace posible este proceso.

No obstante, según Monod (1993), la noción de teleonomía puede llegar a ser paradójica, puesto que implica la idea subjetiva de proyecto, tomando el ejemplo de la cámara fotográfica, cuyo proyecto es captar imágenes, muy similar a la función del ojo de los vertebrados. Éste obstáculo, que pude llegar a tener una aparente ambigüedad, se puede salvar reconociendo que la información necesaria para que un órgano como el ojo sea transmitida con el fin de cumplir una función, con un aparente proyecto, no es más, que la transferencia de información con el objeto de contribuir, así sea, muy indirectamente a la 
sobrevivencia y a la multiplicación de la especie, asegurando la invariancia reproductiva, y por tanto, permitiendo la acción de la selección natural.

Biólogos como Maturana y Varela, aluden que las explicaciones teleonómicas son incluso innecesarias y prescindibles:

"La connotación de diseño a que alude la noción de función, es establecida por el observador y no pertenece al dominio de la maquina misma. En consecuencia si los sistemas vivientes son maquinas autopoiéticas, la teleonomía pasa a ser solamente un artificio para describirlos que no revela rasgo alguno de su organización, sino lo consistente que es su funcionamiento en el campo donde se los observa. Como maquinas autopoiéticas, los sistemas vivos carecen, pues, de finalidad" (Maturana y Varela, 1994. p. 76-77)

No estoy de acuerdo con la supresión total de las explicaciones teleonómicas, debido a que los programas genéticos y todo de lo que ellos se deriva existe en los organismos exista o no observador ${ }^{3}$. Además el "artificio" de la teleonomía puede llegar a ser una excelente herramienta de gran valor heurístico para poder explicar procesos biológicos con aparente finalidad.

Es posible que el concepto de función biológica pueda aparentemente ser de carácter antropocéntrico y teleológico, Biólogos como Atlan argumenta la posibilidad de prescindir de cualquier explicación teleológica:

"El ojo no está hecho para ver, simplemente ve...la noción de función implica que la estructura está adaptada a la función, y todo sucede como si el ojo hubiera sido hecho para ver" (1997, p.44).

Si se tiene una diáfana comprensión de lo que son los procesos teleomáticos o teleonómicos y su clara diferencia con los procesos teleológicos, es muy posible que una comprensión de la teoría de la evolución por selección natural sea más fácil y productiva, puesto que uno de los pilares de dicha teoría es que la selección natural no tiene dirección o finalidad, no ve el futuro, no tiene intenciones o bien "cumple el papel de relojero ciego" (Dawkins, 1988); es decir, posibilita el cambio y desarrollo de ciertas estructuras biológicas pero sin ninguna finalidad u objetivo predeterminado, es el relojero que crea complejos relojes vivos pero que nunca ve o sabe lo que está haciendo.

"La selección natural es un relojero ciego; ciego porque no ve el más allá, no planifica las consecuencias, no tiene una finalidad en mente. Aun así, los resultados vivos de la selección natural nos impresionan de forma irresistible, por su apariencia de haber sido diseñados por un maestro relojero, nos impresionan con la ilusión del diseño y la planificación" (Dawkins, 1988. p.24)

La clave que nos aporta Dawkins, es, que el entendimiento de la selección natural y lo que de ella se deriva, es la base angular para no atribuir diseños, planificaciones o perfeccionamientos de carácter teleológico a la explicación biológica.

¿Por qué las explicaciones teleológicas parecen satisfacer la comprensión de los comportamientos y características de los seres vivos? Existen muchos procesos y estructuras en los seres vivos que cumplen la exigencia de la explicación teleológica, como lo señala Ayala (1998). La mano del hombre, las alas de las aves, los ojos, el comportamiento de cortejo de los pavos reales entre otros, son adaptaciones que pueden,

${ }^{3}$ El autor de este ensayo no comparte en su totalidad las mismas concepciones de objetividadsubjetividad, observador-observado que las de Maturana. 
aparentemente, explicarse teleológicamente debido a que son características aportadas por la selección natural cuando este proceso es erróneamente cargado de una intencionalidad metafísica antropomórfica.

Cuando se explica el desarrollo de las alas no como un órgano que sirve para volar, sino más bien, como un órgano que posibilitó el vuelo contribuyendo al éxito reproductivo de los portadores de esta característica, las alas se convierten simplemente en adaptaciones útiles para los organismos portadores en determinados ambientes $\mathrm{y}$, muy probablemente, haga que dichos portadores dejen mayor descendencia que los individuos que no presenten adaptaciones tan útiles. Así pues, del proceso de selección natural, se puede concluir que no ha sido diseñado conscientemente por nadie, ni mucho menos tiene una finalidad predeterminada. En este sentido, la selección natural es una poderosa herramienta para despojar de teleología a ciertos fenómenos biológicos.

\section{OBSTÁCULO EPISTEMOLÓGICO, TELEOLOGÍA Y ENSEÑANZA DE LA TEORÍA DE LA EVOLUCIÓN POR SELECCIÓN NATURAL.}

De acuerdo con las observaciones que hizo Bachelard (1948), existen grandes dificultades para los estudiantes en la comprensión de algunos principios en la Física, como por ejemplo el de Arquímedes. Sus investigaciones arrojaron resultados con los que se podía argumentar que las dificultades de comprensión de los estudiantes se debían a que existía un choque de modelos mentales, más que a un problema de retención de datos o una profundización del tema. A esta dificultad se le llamaría posteriormente obstáculo epistemológico.

De acuerdo con Hernández (2003), el obstáculo epistemológico no es solamente efecto de ignorancia en un tema, sino que el uso reiterado y anacrónico de un conocimiento anterior que en determinado momento pudo ser adecuado, pero que en el momento actual puede ser inapropiado, constituye un obstáculo que afecta igualmente al estudiante como al profesor.

Del párrafo anterior, se puede inferir, que el uso inadecuado o anacrónico de la teleología en las explicaciones evolutivas se puede convertir en un obstáculo epistemológico que dificultaría la enseñanza de la teoría de la evolución por selección natural.

Ahora bien, de acuerdo con la disertación que se ha hecho en este artículo con respecto a las tres explicaciones de fenómenos evolutivos, como son: las teleológicas, las teleomáticas y las teleonómicas, estas dos últimas parecería que pudieran dar una solución para superar el obstáculo epistemológico generado por la primera. Así tenemos que:

"Un biólogo puede hacer las siguientes afirmaciones sobre este caso o similares:

1) La oruga se dirige a un fin con respecto a las fuentes de luz

2) La función del mecanismo tropístico y el comportamiento que causa es llevar a la oruga hacia la comida

3) En el ambiente normal de la oruga, el mecanismo trópico y el comportamiento que causa son normalmente adaptativos

Las afirmaciones correspondientes apropiadas serían entonces las siguientes:

1') El agente busca la fuente de luz 
2') El propósito de (la intención de, o razón para) buscar la luz es encontrar la

comida.

3') En el ambiente normal, la creencia de que buscar la luz llevara a la comida es normalmente correcta, y conduce al agente a actuar de la manera correcta para conseguir comida". (Wimsatt, 1998, p.479)

Se puede observar claramente que las explicaciones a fenómenos biológicos de carácter teleonómicas son más adecuadas que las de carácter teleológico.

\section{CONSIDERACIONES DIDÁCTICAS}

Explicar las funciones biológicas $\mathrm{y}$, en general todos los procesos biológicos, como el evolutivo, de una manera teleológica o antropomórfica o una mezcla de ambas, es una circunstancia en el proceso de enseñanza-aprendizaje de la Biología que merece especial atención. (Castro y Valbuena, 2007). Es de vital importancia que cuando los profesores de Biología usen algún tipo de lenguaje teleológico, como por ejemplo, para explicar la función biológica, se aclare a los estudiantes, que dichas explicaciones carecen de antropomorfismos como: intencionalidades, objetivos, propósitos, deseos o conciencia, de esta manera se puede adecuar el terreno en la mente de los alumnos para introducir conceptos como el de teleonomía, que es mucho más adecuado para el entendimiento de la teoría de la evolución por selección natural. De esta manera, se puede estar en cierta medida, de acuerdo con López (1996, p. 155) al decir, "Cuando los biólogos emplean lenguaje teleológico, no están necesariamente usando explicaciones antropocéntricas" 4

Pedagogos como Molina (2007) recomiendan no abolir el uso de afirmaciones teleológicas y antropomórficas (en niños), ya que pueden ayudar a mejorar los procesos de comunicación y comprensión en el aula. Molina defiende esta posición parafraseando a Piaget (1951) diciendo que "el uso de lenguaje antropomorfo puede fomentar la subjetividad en niños y jóvenes logrando una visión objetiva de las cosas" (Molina, 2007. pp.88-107) Éste articulo no comparte esta opinión y esta más del lado de el pensamiento Tamir y Zohar (1991) en el que en sus trabajos denotan un interés por demostrar que las teleologías son negativas para el aprendizaje de la Biología, y en particular, para el proceso de enseñanza- aprendizaje de la teoría de la evolución por selección natural. ¿Cuál seria una alternativa? Modestamente, se puede proponer, que de una manera parecida a como Darwin transformo unas concepciones explicativas de gran valor heurístico, encontradas en la selección artificial (de carácter teleológico) para formular su teoría de la selección natural, así mismo, los maestros de Biología podemos direccionar procesos similares en nuestros estudiantes. Lo anterior, obviamente, iguardando y adecuando las proporciones!

\section{CONSIDERACIONES FINALES}

Las argumentaciones teleológicas, tan arraigadas en algunos profesores y estudiantes de Biología, pueden constituir una explicación errónea de algunos fenómenos biológicos, lo

4 El autor de este ensayo recomienda que en vez de decir explicaciones teleológicas carentes de antropocentrismo, se hable abiertamente de teleonomía, y así, de esta manera, introducir conceptos tan importantes como el de programa genético. 
cual puede constituirse en un importante obstáculo epistemológico para el entendimiento de la teoría de la evolución por selección natural. Es importante para superar este obstáculo epistemológico, un claro entendimiento de los procesos teleomáticos y teleonómicos para explicar los procesos biológicos que tienen una aparente intencionalidad y así, de esta manera, dicha comprensión puede posibilitar el entendimiento de la teoría de la evolución por selección natural.

Es importante para estudiantes y profesores de Biología, que al hacer alguna afirmación que explique ciertos fenómenos biológicos, revisarla y escudriñarla para ver si tiene una carga teleológica, en caso de que la tenga, los objetivos serían: primero, el de desterrarla completamente o reemplazarla con alguna afirmación que contenga explicaciones teleomáticas o teleonómicas para explicar dichos fenómenos o como segunda instancia, si la explicación teleológica posee algún valor heurístico, transformarla, despojándola de todo antropocentrismo.

\section{Bibliografía}

- ATLAN, H. 1997. Cuestiones vitales. Entre el saber y la opinión. Tusquets, Barcelona. 205 p.

- AYALA, F. 1998. Teleología y adaptación en la evolución biológica. En Historia y explicación en Biología Barahona y Martínez (Compiladores). Fondo de Cultura Económica, México. 510 p.

- BACARLET, M.; FUENTES R. 2007. Descartes desde Canguihlem: el mecanicismo y el concepto de reflejo. Ciencia Ergo Sum. (España) 14 (2):163-165.

- BACHELARD, G. 1948. La formación del espíritu científico. 12ํㅡ. Ed. Siglo XXl, Buenos Aires. $321 p$.

- CANGUILHEM, G. 1988. Ideología y racionalidad en la historia de las ciencias de la vida. Nuevos estudios de historia y de filosofía de las ciencias. Amorrortu, Buenos Aires. 371 p.

- CASTRO, J. 2003. Los libros de texto: filosofía e historia de la ciencia. Nodos y Nudos, (Colombia). 2(15): 9

- CASTRO, J.; VALBUENA, E. 2007. ¿Qué biología enseñar y cómo hacerlo? Hacia una resignificación de la biología escolar. En: Tecné, Episteme y Didaxis, (Colombia) 1(22): 126145.

- DARWIN, C. 1859. On the Origen of Species. Jhon Murray, Londres. Ed. 509 p.

- DARWIN, C. 2004 [1871]. El origen del hombre ( The Descent of Man and Selection in Relation to Sex). Traducción al castellano en Madrid: Alianza. 523 p.

- DAWKINS, R. 1988. El relojero ciego. Labor, Barcelona. 254 p.

- ECHANDÍA, G. 1995. Aristóteles. Libro Segundo, VIII. Madrid Editorial Gredos, S.A., Madrid. 332 p.

- ENGELS, E. 1982. Die Teleologie des Lebendigen. Dunker \& humblot, Berlin. 189 p.

- HAYES, J. 2000. The Happy Heretic. Prometehus Books, New York. 268 p.

- HERNÁNDEZ, G. 2003. Abatir los obstáculos en el aprendizaje de matemáticas y ciencias. Memorias de la novena reunión de análisis de la actividad experimental en el aprendizaje de las ciencias naturales y exactas. Esteros Editores, Culiacán. 421 p. 
- LÓPEZ, A. 1996. La explicación teleológica en la enseñanza y aprendizaje de la Biología. En: Carreter, M.,Baillo, M., Limon, M., Lopez, A., y Rodriguez, M. Construir y enseñar las ciencias experimentales. Aique, Buenos Aires. $155 \mathrm{p}$.

- MALTHUS, T. 1951. Ensayo sobre el Principio de la Población. Fondo de Cultura Económica, México. 298 p

- MAYR, E. 1974. Teleological and teleonomic. A new analysis. Boston. Studies in the Philosophy of Science. 7 (14): 91-117.

- MAYR, E. 1988. Toward a new philosophy of biology. Harvard University Press, Cambridge. $321 \mathrm{p}$.

- MAYR, E. 1992. The idea of teleology. Cambridge: Journal of Historical Ideas. 3 (53): 117-135

- MAYR, E. 1995. Así es la biología.: Debate, Madrid. 326 p.

- MAYR, E. 2006. Por qué es única la biología. Consideraciones sobre la autonomía de una disciplina científica. Katz, Buenos Aires. 280 p.

- MOLINA, A. 2007. Analogía, pensamiento científica infantil y revalorización de las teleologías y el antroporfismo. En: Tecné, Episteme y Didaxis, Número extraordinario, Tercer Congreso Internacional sobre Formación de profesores de Ciencias, pp.88-107

- MONOD, J. 1993. El azar y la necesidad. Ensayo sobre la filosofía natural de la biología moderna. Tusquets, Barcelona. $342 \mathrm{p}$.

- NAGEL, E. 1977. Teleology revisited: Goal directed processes in biology. New York: Journal of Philosophy. 3 (74): 261-301.

- PIAGET, J. 1951. The child's conception of the world. Littlefield Adam, Savage, MD. 354p.

-SECORD, J. 1997. "Introduction" to Charles Lyell's Principles of Geology, Penguin, Londres. $421 \mathrm{p}$.

- TAMIR, P.; ZOHAR, A. 1991. Anthropomorphism and Teleology in Reasoning about Biological Phenomena. Science Education, 75(1) :57-67.

- WIMSATT, W. 1998. Finalidad e Intencionalidad en la Naturaleza. En Historia y explicación en Biología Barahona y Martínez (Compiladores). Fondo de Cultura Económica, México. $510 \mathrm{p}$. 